\title{
Novos processos de criação literária?
}

Alckmar Luiz dos Santos

UFSC/NUPILL/CNPq

Resumo: Este ensaio quer discutir o estatuto de escritos (isto é, produções apenas verbais, mas não digitais) sobre obras virtuais ainda não (ou já não mais) disponiveis. O que se pretende investigar é se esses textos de apresentação, de especulação e, sobretudo, de esboço e projeto de criaçôes digitais, também podem ser lidos como criaçōes artísticas, ao menos parcialmente. Em outras palavras: os dois escritos que apresento neste trabalho, sobre duas possiveis criaçôes digitais (o "Soneto" e a "Máquina de escancarar janelas"), podem ser lidos como objetos de arte, e de arte literária?

Palavras-chave: criação digital, criação verbal, nova forma de criação

\section{Introdução}

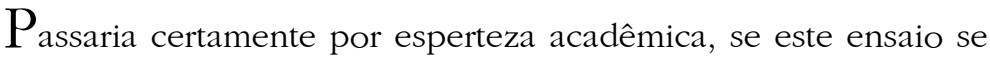
reduzisse apenas a uma lista de tópicos de discussão ou reflexão, alinhavados de maneira mais ou menos coerente:

1. Questões preliminares

2. Alguns antecedentes

3. Exemplos atuais

4. Imaginário e tecnológico 
5. Conclusões preliminares, ou de como seria essa nova forma de expressão artística

Creio que nenhum leitor, mais desavisado que fosse, deixaria de pensar que se trataria de uma estratégia espertalhona para aumentar a quantidade de publicações e engordar o currículo, se eu me limitasse a apresentar um tal esquema, sem seguir adiante na exposição de ideias e na análise de exemplos.

Minha impressão, aliás, é que boa quantidade dos artigos acadêmicos publicados hoje não passam disso, de listas de assuntos e expressões atuais (a bem da verdade, muitíssimo melhores do que essa que apresentei acima), embora disfarçadas debaixo de boas quantidades de citações da moda. Neles, de fato, não se desenvolve autonomamente nenhuma discussão, nenhuma reflexão, não se imprime marca específica alguma a quaisquer argumentos que se possam desenvolver em sua leitura. Se os esprememos até os ossos, não sai nada além de um caldo ralo de expressões feitas, lugares-comuns e intenções teóricas expressas de modo sumário. Ou seja, um conjunto mais ou menos frouxo de tópicos.

Algo muito parecido pode ser dito daquelas manifestações artísticas em que se apresentam apenas suas linhas gerais ou, melhor dizendo, em que se propagandeiam as intenções de seu criador; em que o objeto material que the serve de suporte (quando o há) perde quase toda importância e funciona apenas como meio de propagação de intenções e conceitos mais ou menos vagos. Não é difícil perceber que parte considerável da chamada arte conceitual entra facilmente nessa descrição, ainda que esse rótulo não seja mais tão utilizado como já foi no passado (a denominação, esclareça-se!, não o procedimento; este continua extremamente atual e amiudado).

É claro que essa minha aparente (apenas aparente) má-vontade pode e deve ser melhor investigada e submetida a toda contestação e crítica que se possam levantar contra ela. Comecemos com um contra-exemplo. Permitam-me utilizar aqui, agora, uma pretensa (apenas pretensa) esquizofrenia crítica. O contra-exemplo: há um procedimento muito semelhante a esse, em alguns dos elementos mais interessantes das artes digitais. ${ }^{1}$ Para ser mais preciso, temos uma série de criações digitais em que as descrições do que pode ser feito são extremamente interessantes e ricas, sem que o leitor, por uma série de motivos, chegue a realizar efetivamente

1. De fato, não apenas destas, mas de toda arte que lida diretamente com tecnologia e, por extensão, de toda arte experimental, desde as vanguardas do século XX. 
as operações e utilize as interatividades propostas pela obra. É o que ocorre, atualmente, com a bela criação de Xavier Malbreil, Le livre des morts, disponível em <http://www.livresdesmorts.com/>. De fato, "disponível" não é a melhor palavra, pois já não está nesse sítio aquilo que foi instalado originalmente pelos criadores. Ao acessar a primeira página com conteúdo navegável, os leitores não podem mais participar com sua escrita dentro do Livre, como se fazia ao início. Grosso modo, temos aí, como possibilidade de navegação:

1. entrar em algum das páginas programadas em flash (intituladas Prélude; Etonnement; Chute; Animaux; Désolation; Reconstruction; Abstraction; Renaissance) e ficar observando a criação se desenrolar meio autonomamente diante de nós;

2. ler os escritos propostos nessa versão atual e que não faziam parte da original (talvez melhor fosse dizer primeira): Le livre des morts, les textes de Xavier Malbreil; Une lecture de Xavier Malbreil à l'Université Ouverte de Barcelone, le 16 Avril 2004; Le dossier de presse. Neste último, são descritos mais ou menos detalhadamente as ideias que nortearam a construção do Livre des morts assim como as ações que o leitor poderia fazer dentro dele... Poderia, pois já não pode mais, uma vez que essas possibilidades de interação foram desativadas. Assim, para os atuais e novos leitores da criação de Malbreil, não resta senão imaginar o que aconteceria nas suas interações com a obra, sem interagir de fato com ela. Há alguns elementos que ajudam nessa empreita mais imaginativa que interativa: justamente esses escritos acrescentados a posteriori. Através deles, leitores atuais têm acesso a elementos que ajudam a formular, virtualmente, ações e resultados que não se podem mais implementar. Diga-se de passagem que se trata aí de uma virtualidade segunda (para horror de algum platônico que, porventura, ainda exista!), pois corresponde à virtualização daquilo que, originariamente, já ocorria na virtualidade do digital.

Em linhas gerais, pode-se dizer que temos, nesse caso, uma espécie de defeito que permite, através dessa obra de Xavier Malbreil (no que se refere aos escritos adicionados posteriormente à obra), voltar a instâncias, processos e elementos da tradição impressa, ${ }^{2}$ através da leitura desses novos escritos. Um outro exemplo: Vingt ans après de Sophie Calle. No estado atual dessa obra (que

2. Com o que se comprova, mais uma vez, que o digital não se opõe ao impresso ou ao escrito, mas engloba e assimila, deslocando-os. 
já tive ocasião de discutir em outro ensaio), o defeito é maior: houve perda quase completa da criação original, e as leituras que hoje se podem fazer são intermitentes e propõem espaços de intervenção e de significação que não estavam previstos na proposta original. Estaríamos então dentro do que Philippe Bootz descreveu como uma significação advinda dos "bugs"? Não creio. Levada às últimas consequências, essa aposta significaria um otimismo à Candide, de que uma lógica invisível da tecnologia salvaria os sentidos da obra e, em consequência, nos salvaria de qualquer mediocridade de realização. ${ }^{4}$ Trata-se, longe disso, ao contrário, de uma leitura da obra que fazemos mais aberta, obrigados que somos a incorporar outras instâncias e elementos culturais e tecnológicos, para dar conta dessa carência de possibilidades e de perspectivas trazida pela desinstalação de partes do programa.

Mas a pergunta que deve ser feita e, na medida do possível, respondida é: qual o status artístico dessas estratégias de virtualização (escrita, saliente-se!) do virtual? Em outras palavras, por que funcionaria no meio digital aquilo que, no meu entender, parece não funcionar a contento nas artes do século XX, isto é, um esquematismo apriorístico ou paralelo à arte, guindado à categoria de... arte? Uma hipótese a ser investigada é que o possível estatuto artístico dessas descrições verbais de objetos digitais não realizados, é consequência de termos agora, justamente, uma outra virtualização, no verbal. Trata-se, aqui, de um diálogo de virtualidades, o que não parecia ocorrer com as vanguardas e experimentalismos do século XX em diante. De outro lado, essa dimensão verbal adicionada ao aparato tecnológico, às interfaces, aos processos do digital, propõe espaços de imaginação tecnológica de uma maneira muito diferente da que exercemos efetivamente no dia-a-dia.

Em linhas gerais, os problemas que temos aqui a tratar dizem respeito a 1) virtualizações, a 2) novas aderências entre verbal e digital, a 3) novos exercícios de imaginação tecnológica. É em torno desses polos que se deve deslocar nossas especulações, sem deixar de chamar a atenção para a importância que a palavra adquire nesses casos. Para os que já davam por morta e enterrada a criação verbal, para os arautos de uma pretensa pós-humanidade exclusivamente visual, para esses não pode deixar de ser decepcionante esse revigoramento da antiga arte da escrita, que nos acostumamos a chamar de literatura. De fato, esta pode estar encontrando, nesses casos, novo campo e novas estratégias de expressão.

3. MALBREIL. Le livre des morts.

4. É claro que os argumentos de Philippe Bootz são sofisticados e não têm nada a ver com a ingenuidade com que os descrevo aqui. 


\section{Alguns antecedentes}

No que diz respeito às virtualizações, não pretendo, é claro!, fazer um apanhado histórico desse conceito, o que seria impossível nestas linhas. Vou propor apenas uma investigação mais próxima de algumas aventuras artísticas que parecem cruciais para explorar melhor o campo a que me proponho. É assim que me permito até mesmo simplificar alguns elementos e discutir de maneira panorâmica a revolução, para o bem e para o mal, representada pelas propostas de Marcel Duchamp (afinal, nem Nietzsche está acima do bem e do mal).

No modo como descreve a gênese do artístico em Duchamp, Octavio Paz parece explicitar, mesmo sem se dar conta, a lógica que fundava e, ao mesmo tempo, afundava o projeto do artista francês:

As máquinas são agentes de destruição e daí que os únicos mecanismos que apaixonam Duchamp sejam os que funcionam de modo imprevisível - os antimecanismos. Esses aparelhos são os duplos dos jogos de palavras: seu funcionamento insólito os nulifica como máquinas. Sua relação com a utilidade é a mesma que a de retardamento e movimento, sem sentido e sem significação: são máquinas que destilam a crítica de si mesmas.

Se buscarmos entender melhor essa descrição que o pensador mexicano faz das criações de Duchamp, não é difícil concluir que, por trás delas, poderia estar certa rebeldia romântica contra a tecnologia, espécie de antídoto à tecnofilia futurista, atitude já presente no Dadaísmo (de que participou o mesmo Duchamp). Ora, as máquinas não são apenas ou necessariamente agentes de destruição: para o bem e para o mal (novamente!), são espaços de exercício do imaginário, mais especificamente de um imaginário tecnológico, como aponta, entre tantos, Daniel Cabrera em seu interessantíssimo trabalho. ${ }^{6}$ Tanto ajudam a alimentar a visão (e construir o mecanismo) de uma gigantesca e eficiente engrenagem social, como a das multidões no Reichsparteitag de Nuremberg, quanto servem para fundar uma estética do olhar, isto é, a combinação de plano e movimento na filmagem que Leni Riefenstahl fez do mesmo congresso nazista. A partir disso, não creio que seria muita maldade minha dizer que Duchamp

5. PAZ. Marcel Duchamp ou o castelo da pureza, p. 12-13.

6. CABRERA. Lo tecnológico y lo imaginário. Las nuevas tecnologías como creencias y esperanzas colectivas. 
desenvolve, paradoxamente, uma concepção mecânica (no sentido de limitante e simplificadora) da arte e da estética. Com isso, deixa escapar uma compreensão mais aguda e mais profunda do fazer artístico. Assim como não compreende verdadeiramente o papel da imaginação tecnológica. Ora, em Duchamp, fica difícil aceitar que os aparelhos "são os duplos dos jogos de palavras", pois eles são relegados a secundaríssimo plano, diante do discurso verbal que os cerca, sustenta e, finalmente, os esconde e sufoca; de fato, eles são os condutos para os jogos de palavras (isto é, para sua armadura conceitual). Se bem compreendidos, os aparelhos, para Duchamp, não têm importância alguma, a não ser a de pôr em evidência os discursos e os conceitos do artista, sobre a arte e sobre si mesmo (ele não separava os dois). Por isso, tanto faz construir uma complexa estrutura em metal, madeira e vidro, ou simplesmente pegar uma privada ou uma roda de bicicleta pré-fabricadas. Os jogos de palavras, no final das contas, apenas remetem a si mesmos ou ao próprio artista (o que, no caso de nosso artista, dá na mesma). Os aparelhos, em suma, não importam; daí não se poder afirmar que estes seriam os duplos daqueles. A arte, na visão e no fazer de Duchamp volta-se para uma matéria verbal que é apenas discurso e encenação do próprio artista. Antes de Warhol, já o francês se mostrava especialista em auto-promoção. Quero dizer com isso que, ao partir de maquinismos e chegar ao verbal, Duchamp concentra-se neste último e reduz aquele à mero pretexto deste; o tecnológico, os aparelhos e suas peças não são propriamente significantes que podem alimentar a imaginação tecnológica ou serem alimentados por ela, como parece ocorrer, no meio digital, com as criações que aqui vamos discutir. Por conta disso, estabelece-se, na obra do artista francês (tanto quanto em qualquer arte conceitual), uma primazia do discurso teorizante em detrimento do objeto artístico. Ou, como afirmam uns (e não aceitam outros, entre os quais este vosso escriba), o discurso teórico se guinda à categoria de arte, e no mesmo movimento, furta-se a qualquer contestação, avaliação ou diálogo reflexivo.

Um exemplo algo semelhante ao de Duchamp, mas, dessa vez, dentro da literatura, está na Poesia Concreta, especificamente na ossatura verbal que cerca e sustenta sua criação verbivocovisual. Como considerar ou classificar, por exemplo, o "Plano-Piloto para Poesia Concreta" ?! Ou a legião de artigos críticos e teóricos que acabaram acompanhando, inevitavelmente, as leituras e as análises dos poemas criados pelo grupo?! À diferença do que ocorre com Duchamp, aqui,

7. Disponível em <http://tropicalia.com.br/leituras-complementares/planopiloto-para-poesia-concreta $>$. 
se trata de ir de mecanismos de criação verbais (ademais de vocovisuais) para chegar à verbalidade das teorias, dos artigos teóricos, dos manifestos etc. Retomo e incremento as questões acima: qual o estatuto destes escritos para-poéticos? Seriam apenas teoria e crítica? Ou mereceriam o rótulo de criação literária, como afirmam muitos? Nesse segundo caso, seriam criações estreitamente vinculadas à produção poética ou teriam total autonomia? E, aceitando tal autonomia, como entender e ler os poemas concretos, que, de seu lado, são estreitamente ligados à (se não extremamente dependentes da) própria teoria da poesia concreta?! Em certo sentido, a escrita concreta busca circunscrever ou inferir um maquinismo de produção de significantes a partir de estratégias fundadas num amálgama formado por elementos da comunicação de massas, da comunicação visual, das próprias poéticas visuais, das vanguardas e experimentalismos das artes plásticas e musicais. ${ }^{8}$ Contudo, à diferença de Duchamp, não são "máquinas que destilam a crítica de si mesmas", como afirmou Octavio Paz. Ao contrário, esses escritos teórico-críticos inserem-se coerentemente no maquinismo de produção de significantes da linha de montagem concretista; reafirmam e fortalecem-na, para o bem e para o mal (e lá vamos nós de novo!). Mas, em nenhum momento, há um apagamento ou, no mínimo, um rebaixamento dos maquinismos. O que não quer dizer que se deva aceitar facilmente que toda a produção teórico-crítica possa ser lida e analisada com os mesmos instrumentos que se usam nas leituras das criações literárias.

Podemos dar mais um passo nesse percurso, ao analisar as produções de gente como Raymond Queneau e E. M. de Melo e Castro. Do escritor francês, penso sobretudo no Cent mille milliards de poèmes. ${ }^{9}$ De Melo e Castro, refiro-me a criações como "Tudo pode ser dito num Poema" (ver anexo, ao final). São exemplos já muito trabalhados por mim em outros ensaios, mas vou-me permitir retomá-los aqui, em parte por serem de fato muito relevantes, em parte talvez por hábito ou familiaridade; e uma pontinha de obsessão. Nos dois casos, ambos os escritores

8. Esse amálgama só parece coerente porque se toma o cuidado de apagar evidentes distinções e dessintonias entre seus componentes. Mas essa questão escapa aos objetivos deste trabalho.

9. Algumas imagens desse livro estão em <http://www.google.com.br/images? $\mathrm{hl}=\mathrm{pt}-\mathrm{br} \& \mathrm{client}=$ firefox $-\mathrm{a} \& \mathrm{hs}=2 \mathrm{Dl} \& \mathrm{rls}=$ org $\cdot$ mozilla:pt $-\mathrm{BR}:$ official $\& \mathrm{q}=\% 22$ Cent $\% 20$ mille $\% 20$ milliards $\% 20 \mathrm{de} \% 20$ po $\%$ C3\%A 8 mes $\% 22 \&$ um $=1 \&$ ie $=U T F-$ $8 \&$ source $=0 g \& s a=N \& t a b=$ wi\&biw $=1152 \& b i h=683>$. Uma versão consultável e legível está em <http://www.uni-mannheim.de/users/bibsplit/nink/test/ sonnets.html>. 
constroem maquinismos de produção de significantes. Queneau cria, fisicamente, um livro que é impossível, de fato, de ser lido como livro, pela dificuldade de lidar com suas dez páginas cortadas em tirinhas hostis a manipulações; por outro lado, os sonetos que os leitores podem fazer surgir da combinação delas são ridiculamente inferiores, como sonetos, à maioria dos que já se escreveram e se podem ainda escrever em francês; ao mesmo tempo, são impossíveis de serem totalmente lidos. ${ }^{10}$ O que vai ser lido, então, se é impossível ou inútil ler os sonetos?! - o próprio maquinismo de produção de significantes, que não se pode separar dos sonetos que vão sendo gerados, mas que adquire mais importância do que eles próprios. Em outras palavras, Queneau nos dá a ler, na verdade, um maquinismo físico, seu livro de páginas cortadas, e um maquinismo virtual, o processo de permutações e combinações de versos. E, claro, a justaposição de um maquinismo a outro.

No caso de Melo e Castro, não há nenhuma alteração física no suporte do poema. É a mesma velha e boa página impressa. Contudo, o poeta português cria, por sua vez, um maquinismo totalmente virtual de permutações e combinações, a partir de um algoritmo de combinações, de uma sintaxe mínima estipulando como escolher e associar os elementos propostos e, claro, de uma lista desses elementos, ou seja, de palavras.

Comparando os dois, vemos que se passa de um maquinismo mecânico que dá origem a um virtual, no caso de Queneau, a um maquinismo que é apenas virtual, esboçado ou indicado verbalmente na própria criação, no poema de Melo e Castro. Aliás, é importante chamar a atenção para o fato de que, neste último caso, o poema reduz-se praticamente à descrição verbal do maquinismo de geração de versos (chamemos assim às frases produzidas quando se põe o algoritmo em funcionamento). Ora, ninguém coloca em questão o caráter artístico e especificamente literário da criação de Melo e Castro, mesmo sendo esse poema a descrição de um maquinismo a ser utilizado pelo leitor. A seguir, quero justamente propor exemplos de criações virtuais, em que uma descrição verbal, à imagem do poema do poeta português, é a única via de acesso ao maquinismo. De fato, são criações virtuais em segundo nível, em que a linguagem verbal se encarrega de criar, virtualmente, criações digitais que, por sua vez, sempre são, elas também, virtuais.

10. Como dar conta de ler 100.000.000.000.000 de poemas, ou seja 1.400.000.000.000.000 versos no reles período de uma vidazinha?! 


\title{
Dois exemplos próprios
}

\author{
a. o Soneto
}

[...] Licuit, sempreque licebit, Signatum praesente nota producere nomen. Ut silvae foliis pronos mutantur in annos, Prima cadunt; ita verborum vetus interit actas, Et iuvenum ritu florent modo nata viremtque.

Q. Horatii Flacci, Epistola ad pisones

Um poema aparece num ambiente tridimensional, mas com os versos separados flutuando aleatoriamente pelo ambiente, sem que se pareça, mesmo remotamente, com um soneto. O que se insinua é a possibilidade de reconstruir, em algum momento, de alguma maneira, esse poema, pela reconstituição dos versos na ordem original em que foram escritos. Num primeiro momento, as regras de aproximação entre esses versos serão aleatórias, mas pode-se pensar, posteriormente, em acrescentar algumas variáveis de controle para que o leitor possa interferir nessas aproximações. Em resumo, os versos vão se deslocar através de um espaço tridimensional, adotando comportamento de indivíduos dentro de bandos, gerado por programas que simulem grupos de populações de seres vivos. E, quando os versos se forem unindo, são formados indivíduos híbridos, cujas características serão diferentes, em alguns aspectos, dos indivíduos originais isolados.

Assim, a totalidade do soneto, na sequência das transformações, combinações e comportamentos dos versos, vai sendo reconstruída aos poucos (se é que o será totalmente, em algum momento). No caso, o poema original (que não é mostrado, em nenhum momento, ao leitor; ele nem mesmo sabe que se trata de um soneto) se coloca, então, apenas como um referencial assimptótico (e desconhecido) de chegada. Os versos morrem, desvanecem-se, mas os indivíduos híbridos que se forem formando (combinando verso com outro) vão vivendo um tempo maior ou menor, de acordo com a distância (menor ou maior) que têm do poema-referência-assimptótica. Em outras palavras, os versos viveriam tempos diferentes em função do número de versos agrupados em um mesmo indivíduo híbrido, e em função da distância do poema-referência. E ainda, seria interessante que o sistema fosse gerando aleatoriamente novos versos, à medida que os mais antigos fossem morrendo. Assim, se o verso 1 da primeira estrofe (que poderia ser 
chamado apenas "e1v1") conseguir se associar" ao e1v2, para formar um híbrido e1v1e1v2 (traduzindo: primeiro dístico da primeira estrofe), que é a sequência "esperada" do poema-assímptota, ele vai viver mais tempo do que outros híbridos, como por exemplo o e1v1e1v3 (que não corresponde à sequência de versos do soneto original). Este, por sua vez, vai viver um pouco mais de tempo do que o híbrido e1v1e1v4, e assim por diante. Além disso, quanto maior o número de versos a compor um indivíduo híbrido, maior o seu tempo de duração. Por exemplo, a associação de versos e1v1e1v2e1v3 vive mais tempo do que e1v1e1v2, e assim por diante.

Pode-se pensar num tempo de duração da seguinte maneira: um verso sozinho dura quinze (15) segundos; dois versos em combinação subsequente e1v1e1v2 duram o dobro - trinta (30) segundos, e a progressão segue essa regra (dois versos subsequentes, duração duplicada; três versos subsequentes, duração triplicada). Qualquer combinação de versos não subsequentes, (ex: e1v1e1v3 ou e2v1e1v3), tem a seguinte duração: dois versos (10 segundos), três versos (20 segundos), quatro versos (30 segundos) e assim sucessivamente. É claro que esse tempo de "vida" pode ser fixado pelo sistema, ou se pode introduzir algum controle desses tempos por parte do leitor. Na segunda hipótese, se este aumenta o tempo de vida, diminui correspondentemente a distância mínima para que os versos se possam unir (uma facilidade implica uma dificuldade). E vice-versa: se o leitor aumenta a distância mínima para que os versos de juntem, diminui o tempo de vida deles.

Após se esgotar a duração prevista para a vida dos versos (isolados ou híbridos), eles se desvanecem e caem: as palavras que os compõem se separam e se espalham pelo "chão" do ambiente. Contudo, essas palavras dos versos mortos podem ser capturadas pelo leitor, que construiria, com elas, novos versos. Quando uma palavra de um verso qualquer é capturada pelo leitor, para ser usada na construção de seus próprios versos, as outras palavras desse verso morto ficam mais tempo no chão, por até, digamos, 120 segundos, esperando serem usadas. Após esse tempo, elas também desaparecem.

Seguindo a lógica (e os programas de simulação) de populações animais, os versos criados pelos leitores são predadores dos versos do poema original e apresentam o seguinte comportamento: após serem criados, eles navegam livremente pelo ambiente, mas, sempre que cheguem a certa distância de algum agrupamento, têm o efeito de afastar esses versos do soneto original que se

11. Ou se conseguirmos associá-lo; aí vamos ter que criar regras especiais de associação aleatória. É a mesma questão que indiquei no parágrafo anterior. 
agruparam; eles próprios não vivem em bandos, são predadores solitários. Como a duração dos versos do poema original é uma função do seu agrupamento (quanto mais versos em sequência linear estiverem agrupados, maior a duração desse indivíduo híbrido), o predador, ao separar os versos, diminui automaticamente o tempo de vida dos elementos separados. Um verso predador tem duração de noventa (90) segundos, e ao final desse tempo ele também morre e suas palavras são coladas numa das paredes do ambiente. A morte dos predadores faz, assim, as imagens do ambiente se reorganizarem.

Um soneto foi composto por mim, como elemento inicial para essa criação:

De lembrança, assim, que corpo se faz? Se todo ele se dá sempre e inteiro, Como criar o resto se, primeiro, Só tenho o menos, para ter o mais?!

Todo sem parte, frente sem atrás Não há, é certo, mas como refreio A ânsia de ver teu corpo, perfeito, Se tenho uma parte só, nada mais?!

A distância é muita, o espaço é imenso; Eu só posso colocar poucas partes No seu corpo longe, enquanto o penso.

Que eu aprenda, então, de vez, essa arte De fazer, do pouco e suave, o intenso:

Que eu veja em tudo o que me faz sonhar-te!

Ressalte-se que apenas os leitores deste plano de construção conhecem o soneto na totalidade. Os leitores da criação digital nunca o verão dessa forma. Ademais, é evidente que esse poema quis desenvolver uma tópica bastante frequente na lírica de língua portuguesa, a do afastamento da mulher amada. Mas ela é tratada de maneira a acomodar-se ao que pretendo discutir com a criação digital: a relação entre parte e todo; ${ }^{12}$ ou a maneira de construir sentidos

12. Que é também tema de belo e conhecidíssimo soneto de Gregório de Matos. 
gerais a partir de fragmentos aparentemente caóticos e desconexos. Aliás, a criação abre com a citação de Horácio:

Sempre foi e será permitido criar um nome assinalado com marca do presente. Como as florestas são transformadas por suas folhas com o passar dos anos, caindo as mais velhas, assim se perde a geração antiga das palavras e, como os jovens, florescem as nascidas há pouco e vingam.

Mas a pergunta que pretendo despertar é: "Será assim mesmo?" Talvez se trate aí de uma boa maneira de saber se deus existe... De fato, o que me interessa nesse dispositivo, além do desafio poético-tecnológico, é essa possibilidade de reproduzirmos certa maldade divina de um deus otiosus, que nos solta nesta esfera de vida sem um bom manual de utilização, sem que nos seja dado vislumbrar alguma lógica por trás da poeira de elementos caóticos, faltos de um sentido mais geral, com que lidamos o tempo todo em nossas vidas. De outro lado, ao dar possibilidades de interferência ao leitor (ele pode acelerar o sistema, alterar o ambiente, matar, separar ou juntar versos etc.), ele se torna como que um deus ex machina (que, paradoxalmente, está também dentro do maquinismo todo).

\section{b. a Máquina de escancarar janelas}

Nessa criação, pretendo criar um vírus para Windows (daí a alusão a janelas, no título), que funcione assim: sempre que ele estiver ativado, ao clicar duas vezes sobre qualquer palavra, em qualquer aplicativo rodando no Windows, imediatamente o vírus vai buscar num banco de poemas, um que tenha a palavra selecionada. Se houver mais de um poema, a escolha será aleatória; se não houver nenhuma, a escolha será feita por proximidade de letras, sempre respeitando o princípio do aleatório. E diga-se que o vírus poderá ser ativado ou desativado voluntariamente pelo leitor, a qualquer momento. Após o duplo clique, e feitas as seleções e escolha aleatória de um poema, ele será exibido à frente da janela de leitura, como marca d'água, mostrando-se, mas sem impedir que o leitor possa ver o que estava lendo originalmente.

Ficaria mais ou menos assim: 


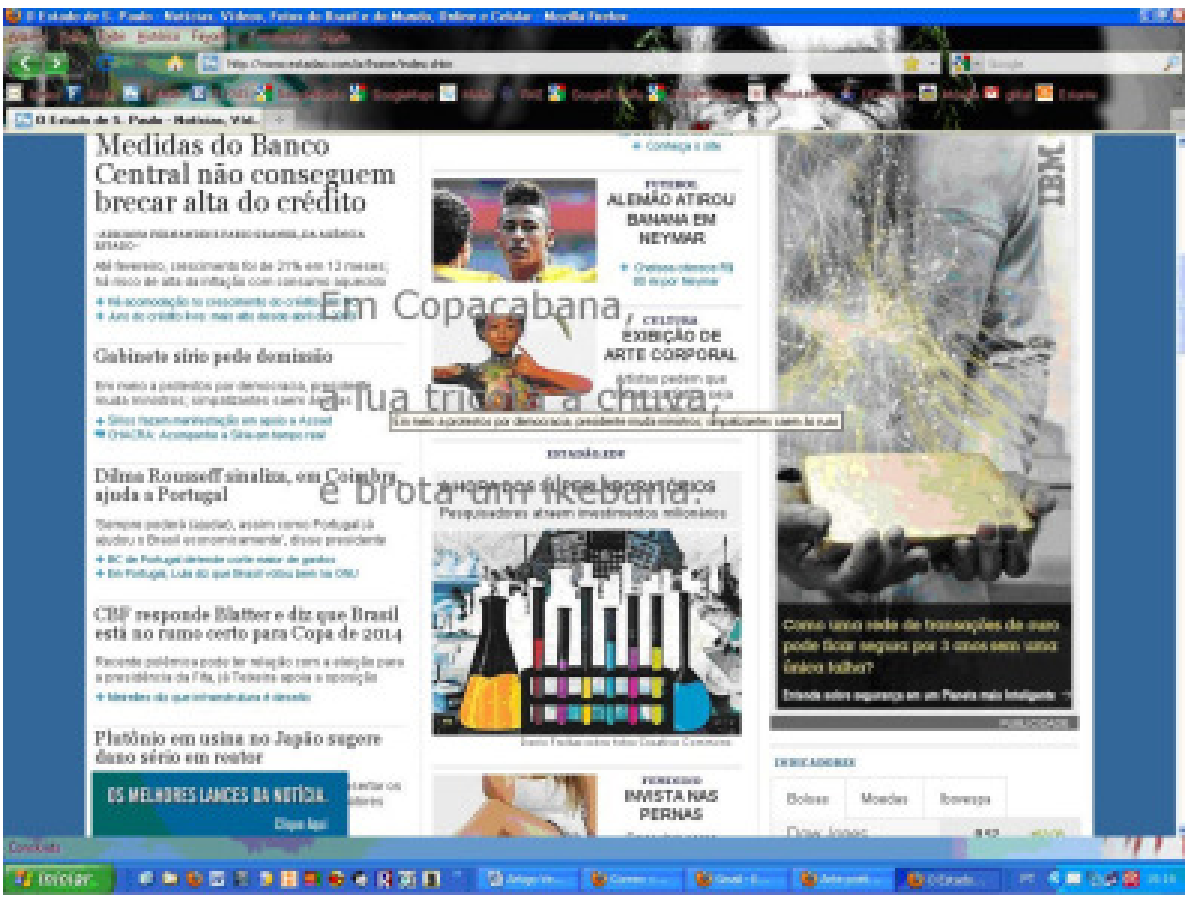

O que pretendo é, evidente!, propor um mecanismo de interferência entre os conteúdos cotidianos e a poesia, rotineirizando parcialmente a linguagem poética e poetizando bastante a linguagem rotineira. É claro que muitos vão dizer que isso já é bastante antigo e foi cavalo-de-batalha da criação literária nos tempos heróicos do Modernismo. Contudo, naqueles momentos, poucos foram os casos em que se propôs uma contraposição imediata e material entre os dois espaços de linguagem. Numa inspeção apressada, não encontro nada além das colagens dadaístas, que, ainda assim, traziam a linguagem (ou o objeto cotidiano) para o espaço artístico. Neste nosso caso, a linguagem cotidiana (vamos chamá-la assim) se mantém completamente em seu espaço de origem... e também se deixa inserir, de modo evidente, no espaço literário. Não pretendo fazer com que o leitor deixe de ler notícias, de escrever imeios, de corresponder-se no Facebook, mas que o faça tendo diante de si a possibilidade de, a qualquer momento (até mesmo inadvertidamente) ver brotar interferências poéticas na tela, diante de si, sobre o que estava vendo. De outro lado, cabe ressaltar que há interferências da linguagem cotidiana na poética: dependendo de onde apareça a imagem dos versos, a leitura e compreensão deles pode ser mais ou menos fácil, exigindo uma atenção muito maior aos versos e bem menor ao que se estava lendo originalmente. 


\section{Tentativas de reflexão}

Dados os dois exemplos, vamos explorá-los criticamente. De concepção (e explicação) mais simples que a do Soneto, a Máquina de escancarar janelas não seria, contudo, de realização muito menos complicada. Mas, num e noutro caso, me parece que se avançaria um pouco mais no caminho em que estão os Cent mille milliards de poèmes e o "Tudo pode ser dito num poema" (além de inúmeros outros, evidentemente!). Uma diferença importante - e já apontada acima - está no fato de que a construção verbal do maquinismo digital justapõe uma virtualização de segundo grau a todo o processo. Outra, está diretamente ligada à tecnologia: enquanto criações como as de Melo e Castro e de Queneau assentam-se em procedimentos (combinatórios e permutatórios) provenientes dos mecanismos básicos da linguagem verbal (ou seja, procedimentos sintagmáticos e paradigmáticos), no caso da Máquina de escancarar janelas, o maquinismo virtual baseia-se em procedimentos nem sempre conhecidos do leitor, tirados de (ou propostos a partir de) um imaginário tecnológico. Imaginário tecnológico que, pela ausência material da obra e pela presença do texto explicativo, vem substituir a programação e a interação direta com as interfaces digitais.

Em outras palavras, é justamente esse imaginário que necessita entrar em ação de forma mais evidente, pela falta de concretização da obra digital. Isso pode ser devido, basicamente, a dois motivos: por carência de recursos tecnológicos (que ainda não existem ou que não estão ao alcance), ou por questões técnicas (falta de competência para utilizar ferramentas e estratégias de programação já disponíveis). Em ambos os casos, a lacuna pode ser preenchida pela imaginação tecnológica: quando a obra digital é materialmente criada, é essa imaginação, por parte dos criadores, que vai alterar os planos iniciais e desenvolver possibilidades de sentido e de interatividade que, ao início, não estavam previstas de forma alguma; quando a obra digital não chega a ser concretizada, é a imaginação tecnológica de criadores e, sobretudo, de leitores que tem de entrar em ação, virtualizando a virtualidade do meio digital, onde a obra seria lida, mas não será (ou não é mais, como no caso do Livre des morts). Contudo, não se trata de um imaginário que venha substituir completamente uma materialidade digital que não foi criada. Longe disso! O que estou apresentando como um possível novo tipo de criação não abre mão do exercício das ferramentas e processos digitais - ainda que não seja para manipular diretamente a própria obra, já que esta ainda não existe 
(ou não existe mais). Repito: o exercício do digital é um pressuposto, como que uma virtualidade que invocamos para acompanhar a leitura da descrição e explanação verbal da futura ou possível criação digital, dando a ela algum sentido mais aberto. Assim, nos casos em que esta não chega nunca a ser construída, o que temos dela são como que fragmentos ou restos de uma totalidade que a matéria verbal nos faz construir virtualmente. Paradoxalmente, porém, é uma totalidade que, de fato, nunca existiu. Um dos papéis da imaginação tecnológica será, então, o de subsumir um todo a que nunca tivemos e, provavelmente, nunca vamos ter acesso, à exata feição do meu soneto acima.

Há ainda outra possibilidade de desenvolver essa criação verbal de que venho falando: agora, não mais em substituição à obra digital, mas paralelamente a esta. Nesse caso, admitamos que a Máquina de escancarar janelas foi efetivamente construída (como espero que será em breve!). Terá havido, aí, uma primeira etapa, em que, após a escrita inicial dos poemas e a subsequente programação do vírus, será provavelmente necessário reescrever partes dos poemas (ou até poemas inteiros), para adequá-los a restrições advindas das necessidades de programação. A partir daí, com o maquinismo digital em funcionamento, passa-se à segunda etapa, isto é, à leitura da obra digital. Nesse momento, será possível e interessante escrever uma descrição das possibilidades de leitura que, nessa segunda etapa, se abrem ao leitor. O esquema seria mais ou menos este:

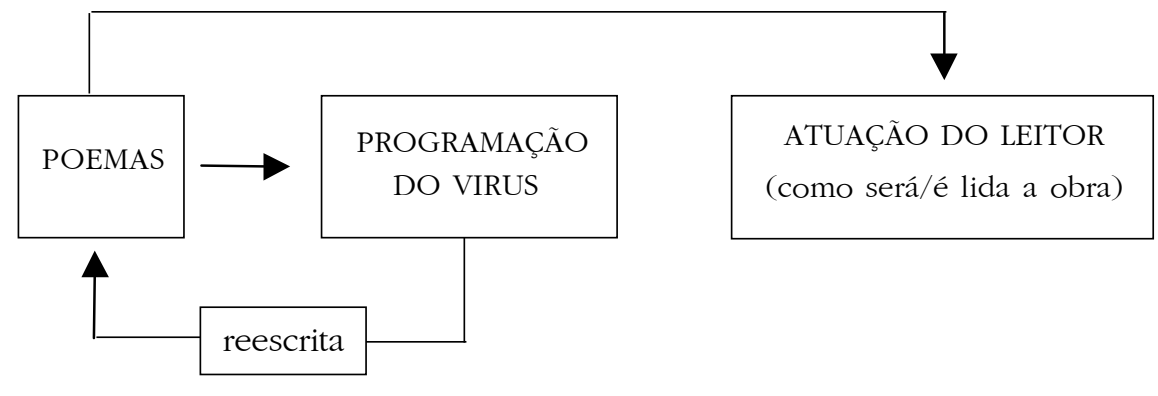

Primeira etapa

Segunda etapa

Teremos aqui uma segunda possibilidade de criação verbal, agora paralela à criação digital, mas abrindo outros campos de sentidos para a criação digital. Ora, apenas essa segunda criação verbal poderia dar conta de justapor as duas etapas acima apresentadas. E ressalto que não se trata necessariamente de uma descrição ou de um manual de utilização. É muito mais do que isso. O que proponho aqui, mais uma vez, é utilizar a expressão verbal para construir maquinismos virtuais, de que o leitor, agora, é chamado justamente a manipular, ancorado em seu 
imaginário tecnológico (isto é, não propriamente na maneira como usa fisicamente, mas como entende e faz significar maquinismos e processos técnicos). E, de fato, apenas essa obra verbal, virtualizando os procedimentos de criação e de programação, poderia dar aos leitores uma leitura conjunta das duas etapas acima mencionadas.

Ora, como podemos entender isso que disse acima - a virtualização dos procedimentos de criação e de programação? Essa operação passa por uma espécie de ficcionalização do tecnológico, virtualizando-o e deslocando-o de seu locus cultural. Não mais submetido a uma lógica do fazer ou da manipulação direta, mas a uma lógica do expressar. É aí que outra complexidade do tecnológico vem à tona, mas não mais aquela habitual que nos assusta com nossa ignorância dele. Ele aparece, agora, para nos assustar com a ignorância que ele próprio tem de nós. É como se o digital adquirisse uma verdadeira estrutura mítica; ${ }^{13}$ como se a criação verbal a ele associada fosse um apropriação ritualística da tecnologia. Não por acaso, várias criações digitais dos últimos anos tem insistido nessa ritualização do tecnológico, a exemplo das de Gilbertto Prado (caso específico e evidente de Desertesejo), Tânia Fraga, Diana Domingues e muitos outros.

No nosso caso, dentro do que chamamos de criação literária, essa ritualização pode ser entendida como o processo de gerar novas e até surpreendentes aderências entre a aparente vetustez do verbal e a pretensa constante novidade do digital. De fato, se são mesmo possíveis, novos processos de criação - apontados no título deste trabalho - seriam como que ritualizações realizadas através de exercícios de fortalecimento e de autonomização de nossa imaginação tecnológica. Ao inserir a matéria verbal em instâncias ou processos em que ela não aparecia antes, desdobramos virtualizações e podemos propiciar o surgimento de outras relações entre verbal e digital, em que um não domine o outro. Mais ou menos como procurei descrever aqui, nesta tentativa de ensaio. Voltando ao nosso velho Horácio, são novas folhas que parecem nascer inesperadamente do húmus das velhas. Resta saber se darão frutos (ter certeza absoluta disso já escapa a minhas parcas competências)!

13. Não o falso mito contemporâneo de uma tecnologia todo-poderosa, que os técnicos se comprazem em apregoar (como já apontei em outros escritos), mas um verdadeiro mito da atualidade. 


\section{New processes of literary creation?}

Abstract: This paper wants to discuss the status of writings (i.e., texts which are only verbal, but not digital) on virtual works which are not yet (or no longer) available. The aim is to investigate whether a text that presents, speculates, outlines, and designs digital creations can also be read, at least partially, as an artistic creation. In other words, would it be possible to consider as objects of art the writings I present here about two digital creations (the Sonnet and the Window wide opening machine)?

Keywords: digital creation, verbal creation, new ways of creating

$$
\text { Referências }
$$

CABRERA, Daniel. Lo tecnológico y lo imaginário. Las nuevas tecnologías como creencias y esperanzas colectivas. Buenos Aires: Biblos, 2006.

MALBREIL, Xavier. Le livre des morts. Disponível em: <http://www.uottawa.ca/ academic/arts/astrolabe/articles/art0037/Lisibilite.htm>. Acesso em: 21 nov. 2011.

PAZ, Octavio. Marcel Duchamp ou o castelo da pureza. 2. ed. São Paulo: Perspectiva, 1997. 
ANEXO

"Tudo pode ser dito num Poema", de E. M. de Melo e Castro (em Álea e Vazio, Lisboa: Moraes Editores, 1971).

1) propõe-se o seguinte modelo

$$
\text { em presença }
$$

acaso A é B de A (ou de B, ou de C, etc.)

na ausência

2) A e B são um par de contrários
exemplos:
tudo - nada
bem - mal
alto - baixo
belo - feio
preto - branco
etc. etc.

3) A e B são substantivos ou pronomes

exemplos:

$\begin{array}{ll}\text { homem - } & \text { deus } \\ \text { arma - } & \text { braço } \\ \text { casa - } & \text { fogo } \\ \text { amor - } & \text { vento } \\ \text { eu - } & \text { tu } \\ \text { tu - } & \text { ele } \\ \text { etc. } & \text { etc. }\end{array}$

4) C é aleatório

5) escolha as suas palavras e desenvolva o modelo segundo uma regra combinatória

6) estude atentamente as proposições resultantes 
7) não suspenda a sua pesquisa: tudo pode ser dito num poema

EXEMPLOS $^{14}$

acaso tudo é nada em presença de tudo

acaso nada é tudo em presença de tudo

acaso tudo é nada em presença do nada

acaso nada é tudo em presença do nada

acaso tudo é tudo em presença de tudo

acaso tudo é tudo em presença do nada

acaso nada é nada em presença de tudo

acaso nada é nada em presença do nada

acaso tudo é nada na ausência de tudo

acaso nada é tudo na ausência de tudo

acaso tudo é nada na ausência do nada

acaso nada é tudo na ausência do nada

acaso tudo é tudo na ausência de tudo

acaso tudo é tudo na ausência do nada

acaso nada é nada na ausência de tudo

acaso nada é nada na ausência do nada

acaso tu és tu em presença de ti

acaso tu és tu na ausência de ti

acaso tu és ele na presença de ti

acaso tu és ele na ausência de ti

acaso ele é tu na presença de ti

acaso ele é tu na ausência de ti

acaso ele é ele na presença de ti

acaso ele é ele na ausência de ti

acaso tu és tu na presença dele

acaso tu és tu na ausência dele etc.

14. Esses exemplos foram gerados a posteriori, após a publicação do livro e constam da edição do poema em Antologia efêmera, São Paulo: Lacerda Editores, 2000. 